\title{
Age validation, growth estimation and cohort dynamics of the bony flying fish Hirundichthys oxycephalus off eastern Taiwan
}

\author{
Chih-Wei Chang ${ }^{1,2, *}$, Chung-Hui Lin ${ }^{3, *}$, Yung-Song Chen ${ }^{4}$, Meng-Hsien Chen ${ }^{5}$, \\ Shui-Kai Chang ${ }^{3, * *}$
}

\author{
${ }^{1}$ National Museum of Marine Biology and Aquarium, Pingtung 944, Taiwan, ROC \\ ${ }^{2}$ Institute of Marine Biodiversity and Evolutionary Biology, National Dong Hwa University, Pingtung 944, Taiwan, ROC \\ ${ }^{3}$ Institute of Marine Affairs, National Sun Yat-sen University, Kaohsiung 804, Taiwan, ROC \\ ${ }^{4}$ Department of Animal Science, National Ilan University 260, Ilan, Taiwan, ROC \\ ${ }^{5}$ Department of Marine Biotechnology and Resources, National Sun Yat-sen University, Kaohsiung 804, Taiwan, ROC
}

\begin{abstract}
Flying fishes (Exocoetidae) are commonly found in the epipelagic zone and play an important role in Taiwan in maintaining the stability of the marine ecosystem, local culture and coastal fisheries. However, little is known about their biology and life history, even though several species are of important commercial value in western Pacific countries. Overexploitation of one of the dominant species, the bony flying fish Hirundichthys oxycephalus, is a critical issue in the fishery management and resource assessment of this species. In the present study, $H$. oxycephalus eggs were harvested off northeastern Taiwan, while adult fish were collected mainly off the southeastern coast of Taiwan. We validated the daily periodicities of the growth increments in 3 otolith pairs based on the successive otolith examination of fish reared in the laboratory from fertilized eggs. The asteriscus was determined to be the most suitable otolith for age determination of the fish. Age (in days) was calculated by counting the number of growth increments on the mounted otolith and adding 11. By using a growth coefficient of $0.0075 \mathrm{~d}^{-1}$, the asymptotic length of these fish was estimated to be $253.86 \mathrm{~mm}$. Back-calculated hatching dates indicated that an occurrence of the summer spawning cohort coincided with the known egg-fishing season off the northeastern coast. On the other hand, the source of the adult fishery off the southeastern coast originated from a new winter spawning cohort. The cohort dynamics of this species were found to be more complicated than previously thought. Our findings could be added to the information already known about the reproductive ecology of $H$. oxycephalus and used to improve the fisheries management of these fish.
\end{abstract}

KEY WORDS: Hirundichthys oxycephalus $\cdot$ Otolith $\cdot$ Age and growth $\cdot$ Hatching date $\cdot$ Cohort dynamics

Resale or republication not permitted without written consent of the publisher

\section{INTRODUCTION}

Flying fish belong to the family Exocoetidae and form an epipelagic group of fishes that are distributed worldwide in both tropical and subtropical waters (Bruun 1935, Oxenford et al. 1995). These fishes are an intermediary in the bioenergetic transfer, where the flying fish exists as a low-level consumer feeding mainly on zooplankton and occasion- ally on small fish (Lipskaya 1987). The flying fish is also the main prey for the dolphinfish Coryphaena hippurus and various tunas (Rose \& Hassler 1974, Oxenford \& Hunte 1999, Wu et al. 2006). In addition to its fundamental ecological relevance, the flying fish is also an important component of traditional fisheries and is treated as a cultural emblem in the countries of the Caribbean Sea and the southern Pacific, as well as in South and Southeast Asia 
(Zerner 1986, Dalzell 1993, Resosudarmo 1995, Potts et al. 2003, Blake \& Campbell 2007).

Among the 8 genera and 52 species of flying fishes in the world (Nelson 2006), 7 genera and 26 species (Shao 2009, but this may increase to 29 species according to Chang et al. 2012), are recorded mainly off the eastern coast of Taiwan, which is influenced by the Kuroshio Current. The primary target of the flying fish fishery in Taiwan is to capture adults by drive-in net, gillnet, and set net fisheries off the eastern and southwestern coasts of Taiwan. Another important harvest of this fishery is flying fish eggs, in which the ovulating fish attach onto artificial spawning substrata in waters off the northeastern coast. The fishing season for adult flying fish runs mainly from March to June off Taiwan's east coast, with an average annual catch of approximately $420 \mathrm{t}$. The egg fishery runs from April to July and has an annual harvest of $228 \mathrm{t}$ (Anonymous 2010).

The bony flying fish Hirundichthys oxycephalus is a widely distributed fish whose range is the IndoWest Pacific from the Arabian Sea to southern Japan, New Guinea and New South Wales, Australia. It is a relatively small-sized flying fish and is one of the main species of flying fishes in Taiwan. In northeastern Taiwan, their eggs are harvested primarily for food consumption, while in southeastern Taiwan the adults are used as bait fish in the long-line and trolling fisheries. The increased harvest pressure on both the adult populations as well as the eggs is due to overexploitation during the months of May and June, and this has become a crucial issue for the Department of Fisheries in Taiwan. To assess the situation, managers will have to apply models such as survivor analysis, virtual population analysis and age-based stock assessment. All of these models require the use of parameters that are derived from the age and growth data from these fish. Also, the possible relationship between parents and recruits of this exploited species needs to be elucidated. However, there is a substantial lack of baseline studies pertaining to the biology and ecology of the flying fishes inhabiting the waters off the coast of Taiwan.

The age and growth of the flying fishes Hirundichthys affinis of Barbados and Oxyporhamphus micropterus of the Philippines have been studied using length-frequency distribution analysis (Lewis et al. 1962, Yacapin 1991). Brothers (1980) confirmed that the microstructure in the otolith of the Exocoetidae was suitable for age and growth studies. Bony fishes have 3 pairs of otoliths, namely the lapillus, asteriscus and sagitta. Campana et al. (1993) estimated the longevity of $H$. affinis by using sagitta
$\mathrm{Th}^{228} / \mathrm{Ra}^{228}$ radiometric dating. Oxenford et al. (1994) studied the age and growth of $H$. affinis by analyzing the growth increments in the lapillus. Yoneyama (2001) used the asteriscus for determining the age of flying fish in the coastal waters off eastern Japan. Ichimaru (2005) compared the growth increments in both the sagitta and the lapillus of Cypselurus heterurus, $C$. hiraii and $H$. oxycephalus off the northeastern coast of Japan, with the lapillus being used to determine the age of the fish. Generally speaking, even though the otolith pairs selected for age determination differed between studies, all otolith-related studies indicated that flying fishes were quite short-lived and had a relatively rapid growth, which had been previously indicated by the length-based method.

As indicated above, about $50 \%$ of flying fishes are distributed in the waters off Taiwan (Nelson 2006, Shao 2009, Chang et al. 2012), but none of them have yet been studied for age and growth. The aim of the present study was to use otolith analysis to determine the age and growth of the important bony flying fish found off the eastern coast of Taiwan and to backcalculate age to the spawning date to determine the cohort dynamics. In order to determine the age in days, the microstructure showing the daily rings in the otolith must be clearly visible. One of the 3 pairs of otoliths - the sagitta, asteriscus or the lapillus must be empirically designated as the most suitable for determining the age of that particular type of fish. In addition, the first growth ring and the daily periodicity of the subsequent growth increments in the otolith should be rigidly validated. Thus, before collecting data from the wild-caught fish, we conducted a laboratory control to test our ability to fulfill the above-mentioned requirements.

\section{MATERIALS AND METHODS}

\section{Sampling design}

A hatching experiment and an at-sea survey program were conducted to obtain flying fish samples for the present study. Fertilized flying fish eggs for the hatching experiment were collected from the artificial spawning substratum off Keelung Island $\left(25^{\circ} 12^{\prime} 14.43^{\prime \prime} \mathrm{N}, 121^{\circ} 48^{\prime} 38.67 " \mathrm{E}\right)$ in northeastern Taiwan on 17 July 2009 (Fig. 1). Within a 5 h period, the eggs were transferred from the sampling site partly to the laboratory at the College of Marine Sciences (CMS), National Sun Yat-sen University in southwestern Taiwan and partly to the Marine Research Station (MRS), Institute of Cellular and 


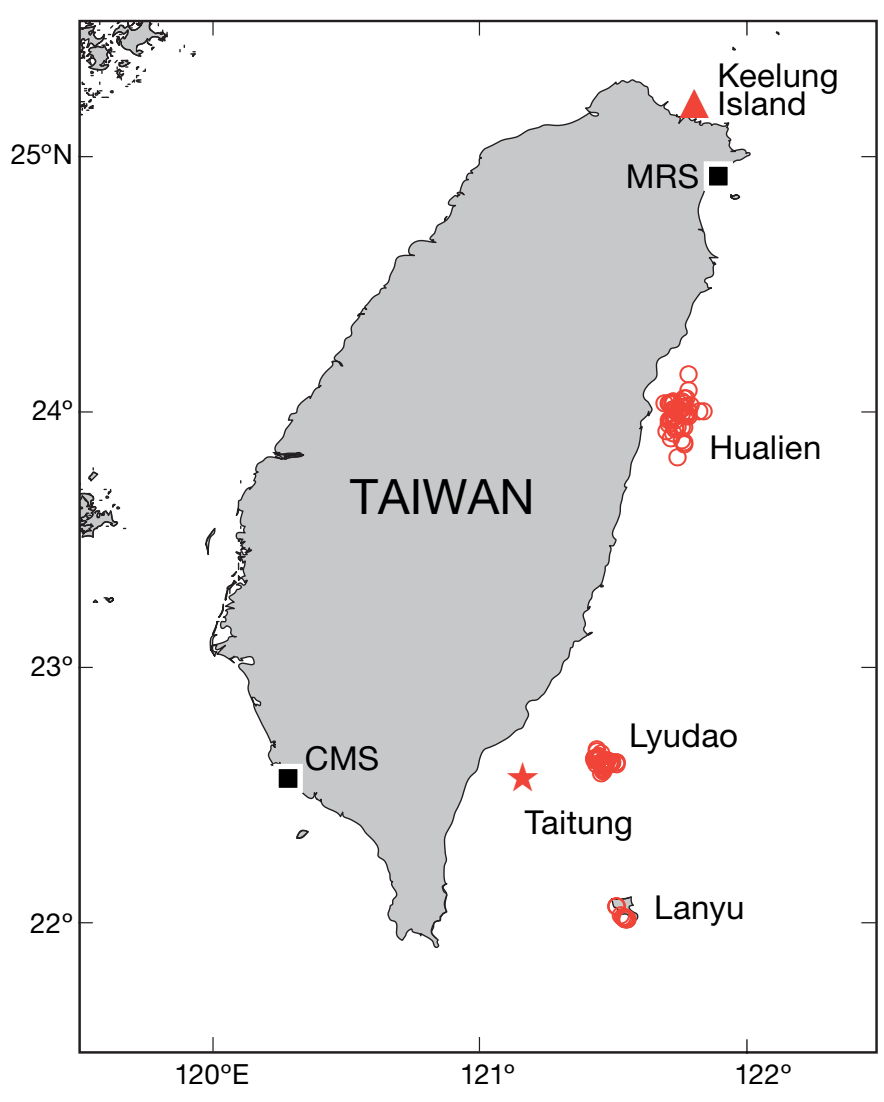

Fig. 1. Hirundichthys oxycephalus. Sampling sites and experimental affiliations for bony flying fish in Taiwan. Triangle: fertilized eggs; star: wild juveniles; circle: wild adults. CMS: College of Marine Sciences, National Sun Yat-sen University; MRS: Marine Research Station, Institute of Cellular and Organismic Biology, Academia Sinica

Organismic Biology, Academia Sinica in northeastern Taiwan. Healthy eggs were selected after microscopic examination. They were then reared in a 1000 1, circular outdoor tank made of polyester, under natural photoperiod, temperature $\left(24\right.$ to $29^{\circ} \mathrm{C}$ during July to November), and salinity (28 to 35 ) conditions. The large range in salinity was due to the fact that the tank was not covered and thus exposed to natural weather conditions.

The eggs hatched after $3 \mathrm{~d}$ and the hatched larvae were gradually transitioned to feed upon rotifers, copepods and artificial feed. The fish were assumed to be well adapted to artificial rearing, since a gradual development and pigmentation of the fins and trunk occurred. The laboratory-reared fish were confirmed to be the bony flying fish by comparing the species characteristics to those outlined in the identification key of Exocoetidae fishes in the Pacific Ocean (Chen 1987). A total of 87 fish were sacrificed within the 46 rearing days in CMS, and 21 fish were sacrificed within 203 days in MRS for the daily periodicity validation studies. The maximum lengths of the reared fish were $46.9 \mathrm{~mm}$ and $78.6 \mathrm{~mm}$ in CMS and MRS, respectively.

For the at-sea surveys, flying fish were collected from the coastal waters of southeastern Taiwan at 4 sites: Hualien, Taitung, Lyudao and Lanyu (Fig. 1). The majority of the fish samples were collected by daytime gillnetting between April 2009 and March 2010 in Lyudao, on some occasions between April and November 2009 in Hualien and between April and July 2009 in Lanyu. A gillnet set was $3.6 \mathrm{~m}$ wide and consisted of 3 nets of 65,70 and $120 \mathrm{~m}$ in length with mesh sizes of 5.6, 4.0 and $2.8 \mathrm{~cm}$, respectively. A total of 109 hauls were conducted during this study, 73 in Lyudao and 36 in Hualien. A small proportion of samples were collected by using a hand net under light attraction during the nighttime between May and June 2009 in Taitung and Lanyu.

The purpose of the sample collection was to obtain individuals of various sizes for age and growth analysis. Consequently, the effects of the various mesh sizes and fishing efforts for each region were not adjusted. Species identification of the flying fish species followed Chen (1987), Shen et al. (1993) and Shao (2009). The fork length (FL) and body weight (BW) of the fish were measured.

\section{Otolith preparation and examination}

The otoliths of early larvae were localized and their formation sequences were observed by microradiography (XL-100, Laiko), under the operating condition of $40 \mathrm{kV}$ and $3 \mathrm{~mA}$ for a $5 \mathrm{~s}$ exposure time. For the purpose of microstructural analysis, otoliths were extracted, cleaned and air-dried. All 3 pairs of otoliths from the laboratory-reared fish, as well as both the lapillus and the asteriscus from the wild-caught fish were directly mounted on a glass slide with DPX mountant (J.T. Baker) for histology in the sagittal plane, and were examined under a light microscope. The sagittal otoliths of the wild-caught fish were embedded in epoxy, and subsequently the sagittal, frontal and transverse planes of the otolith were prepared for microstructural examination. The sagittal plane of the otolith was exposed by using a variable speed grinder-polisher (Metaserv 2000, Buehler) with various grit sandpapers, $0.05 \mu \mathrm{m}$ alumina slurry and polishing felt until the primordium was clearly visible. The frontal and transverse planes of the otolith were exposed by means of a double sectioning 
procedure using a low speed saw (Isomet, Buehler) followed by the same polishing protocol described above for both sides of the otolith section. A solution of $5 \%$ EDTA was applied for 10 to $30 \mathrm{~s}$ to etch the otolith surface and to reinforce the contrast of the otolith growth increments when viewed under a light microscope. The growth increments of each otolith were read at least 3 times, and the mean value with a $<5 \%$ deviation was used to represent the final count.

\section{Data analysis}

The relationship between the growth increments in the otoliths and the number of rearing days posthatch of the laboratory-reared fish were calculated by linear regression. The von Bertalanffy growth equation for the fish, computed by their FL and age (in days), were fitted by non-linear regression. Hatching dates of the wild-caught fish were backcalculated from the date of collection. In this study, the eggs of the bony flying fish hatched $3 \mathrm{~d}$ after fertilization. Thus, the spawning dates of the fish could be back-calculated to have occurred $3 \mathrm{~d}$ before the hatching date. The difference of the mean values among groups was tested by 1-way ANOVA and Tukey's multiple-comparison test at a significance level of $95 \%$.

\section{RESULTS}

\section{Otolith microstructure}

The 3 pairs of flying fish otoliths did not form simultaneously. The sagitta and the lapillus could be observed immediately after hatching, while the asteriscus was not visible until the tenth day post-hatch (Fig. 2). Growth rings of the 3 otolith pairs of the fish are shown in Fig. 3. The growth increments in the mounted sagitta were only visible in fish with a FL of less than approximately $30 \mathrm{~mm}$ (Fig. 3a). For fish with a longer FL the daily growth increments could only be determined in the polished sagitta (Fig. 3b). Fish with a FL longer than $65 \mathrm{~mm}$, however, tended to have otoliths with an overburden of an increased thickness and high opacity, making it difficult to distinguish the daily growth increments in the sagittal, frontal or transverse sections of the otolith. Similarly, the daily growth increments in the mounted lapillus for fish with a FL of less than $40 \mathrm{~mm}$ were easily visible (Fig. $3 \mathrm{c})$. However, the polished otolith was required for fish over $40 \mathrm{~mm}$ (Fig. 3d). On the other hand, the daily
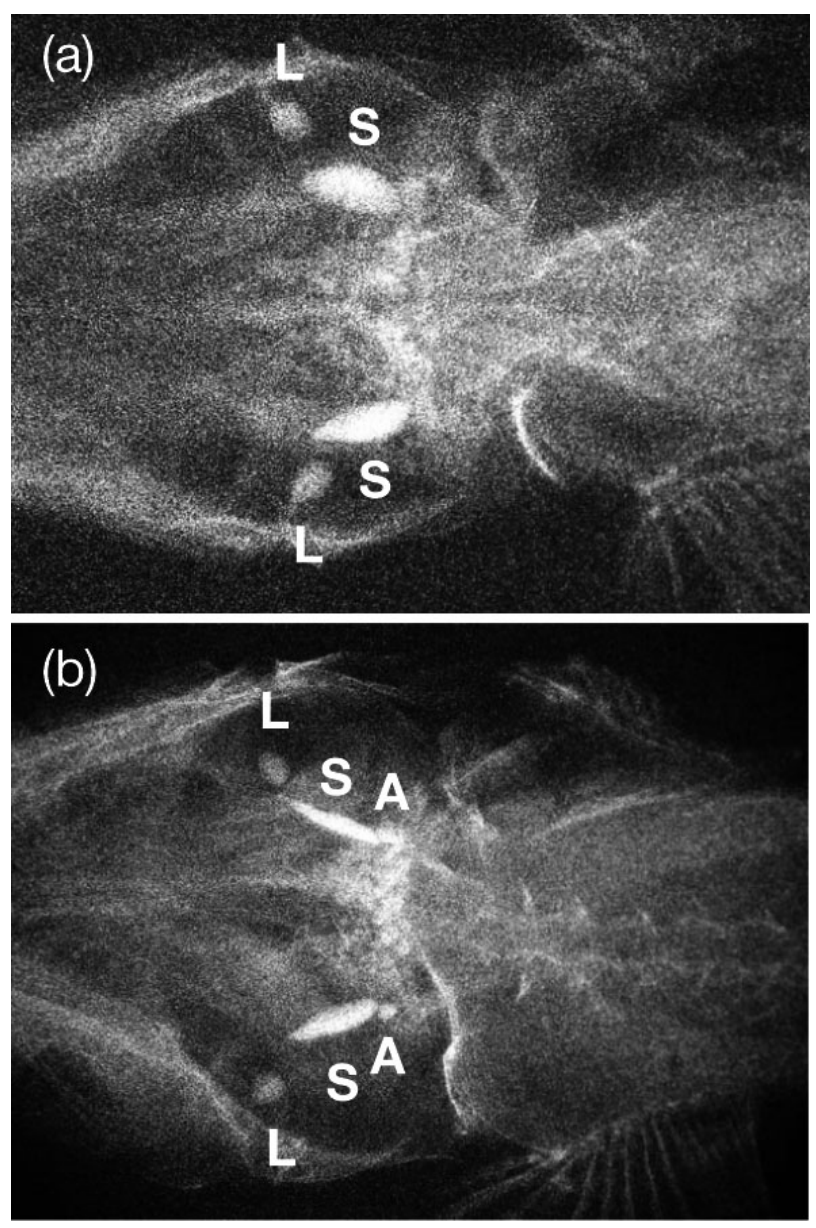

Fig. 2. Hirundichthys oxycephalus. Microradiography of the otolith locations of bony flying fish at (a) $10 \mathrm{~d}$ posthatch and (b) $15 \mathrm{~d}$ post-hatch. L: lapillus; S: sagitta; A: asteriscus

growth increments in the asteriscus were clearly visible for fish of all sizes and could be determined by examining the mounted otolith (Fig. 3e,f).

\section{Validation of the otolith daily growth increment}

The age of 62 fish from the 203 rearing days was determined. The rates for successful age determination were $73 \%$ for the sagitta, $92 \%$ for the lapillus and $97 \%$ for the asteriscus. The relationships between the daily growth increments in the otoliths $(y)$ and the number of rearing days after hatching of the fish $(x)$ were fitted as follows (Fig. 4).

Sagitta: $y=1.008 x-0.058\left(n=48, R^{2}=0.997\right)$

Lapillus: $y=0.991 x-0.055\left(n=58, \mathrm{R}^{2}=0.997\right)$

Asteriscus: $y=1.004 x-11.041\left(n=61, R^{2}=0.998\right)$ 

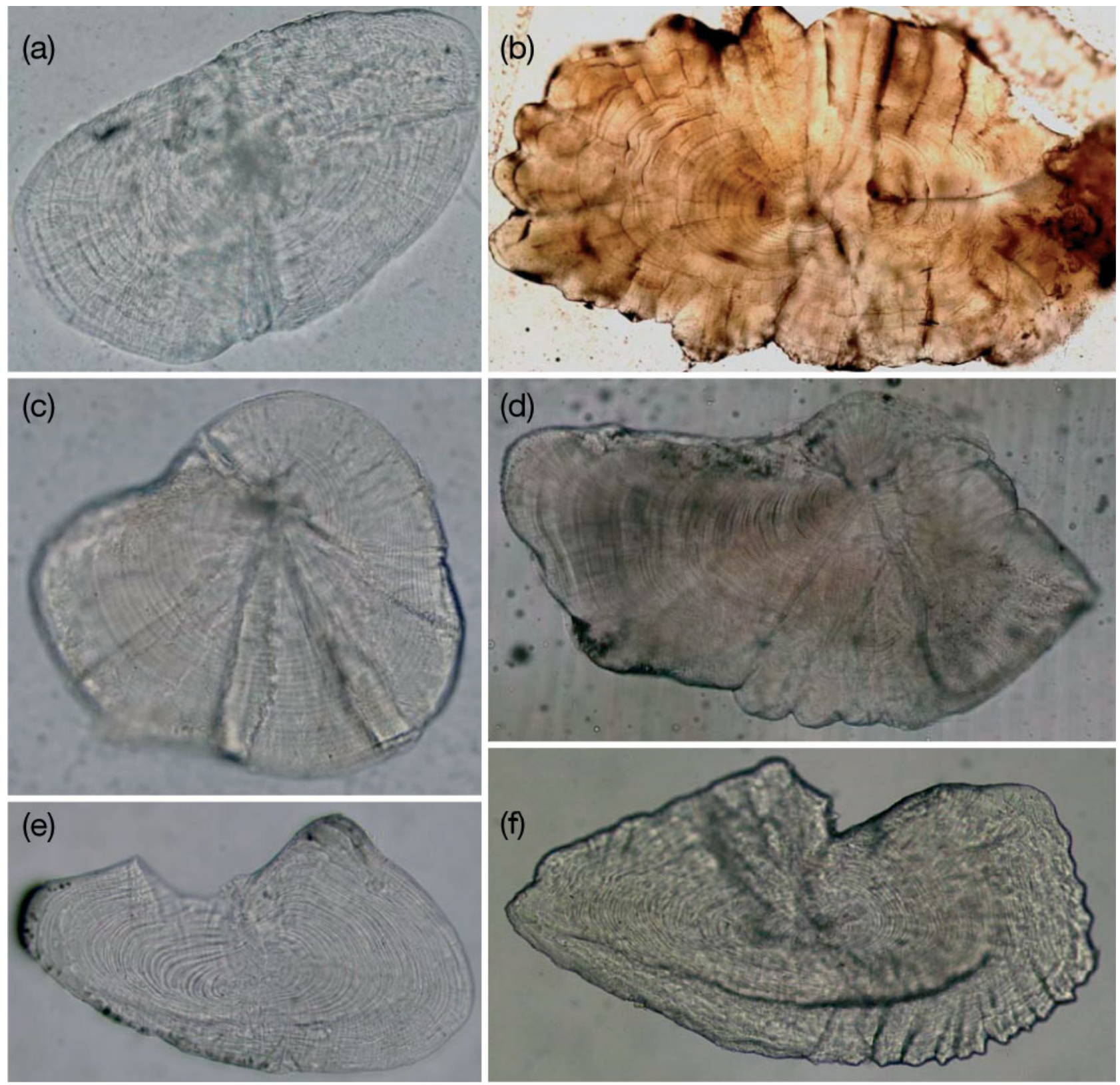

Fig. 3. Hirundichthys oxycephalus. Growth increments in the $(\mathrm{a}, \mathrm{b})$ sagitta, $(\mathrm{c}, \mathrm{d})$ lapillus and (e,f) asteriscus of bony flying fish as observed in the mounted otolith ( $\mathrm{a}, \mathrm{c}$, e and f) and the polished otolith (b and d). Fish fork lengths were (a) 18.81, (b) 46.90, (c) 54.21, (d) 132.97, (e) 54.21 and (f) $155.01 \mathrm{~mm}$

The slopes for the 3 equations were not significantly different from 1 ( $t$-test, all $\mathrm{p}>0.05$ ). This supported the finding that the growth increments in the 3 otolith pairs were deposited at a constant daily rate. Therefore, the increments in the otoliths could be regarded as daily growth increments (DGIs). The intercepts of 0.057 for the sagitta and 0.055 for the lapillus did not differ from 0 , indicating that the first DGI in both the sagitta and the lapillus formed the first day after the fish were hatched (Fig. 4a,b). However, the intercept of 11.040 for the asteriscus indicated that the first DGI was deposited $11 \mathrm{~d}$ post-hatch (Fig. 4c).

Considering the lower complexity involved in otolith preparation as well as the higher success rate in age determination, examining the asteriscus by using the mounted otolith was chosen as the most suitable protocol for determining the age of the bony flying fish. 

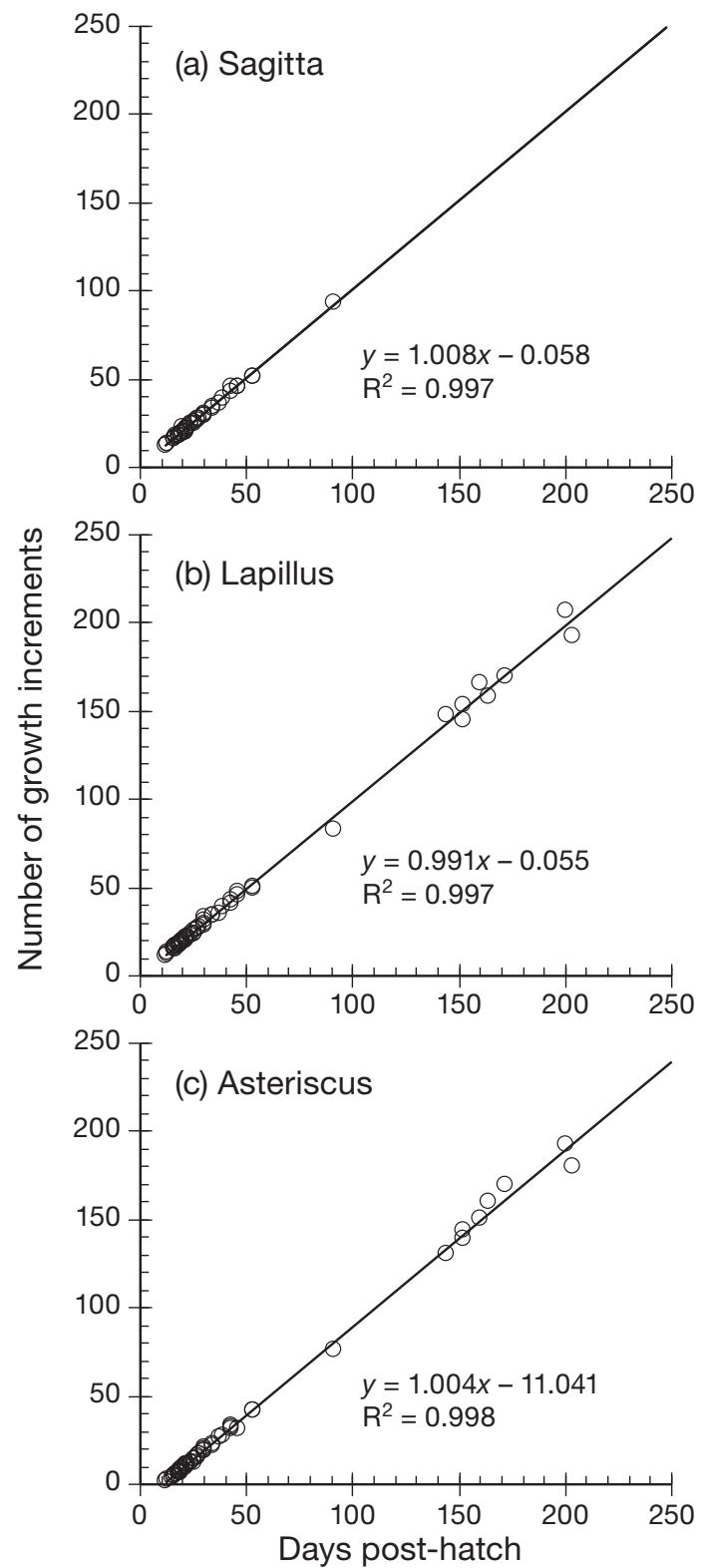

Fig. 4. Hirundichthys oxycephalus. Relationship between otolith growth increments in the (a) sagitta, (b) lapillus and (c) asteriscus and the number of days after hatching of bony flying fish

\section{Length, age and growth of the bony flying fish}

A total of 189 bony flying fish were identified off the eastern coast of Taiwan during May and November 2010 (Table 1). Among them, one juvenile fish with a FL of $54.0 \mathrm{~mm}$ was collected in Taitung in May. The others were adult fish and were collected on 5 occasions. The FLs (mean \pm SD) of these fish was $224.4 \mathrm{~mm}(\mathrm{n}=1)$ in Hualien in May, $190.3 \pm$ $5.2 \mathrm{~mm}(\mathrm{n}=3)$ in Lanyu also in May, $186.5 \pm 9.3 \mathrm{~mm}$ ( $\mathrm{n}=35)$ in Lyudao in June, $159.6 \pm 23.1 \mathrm{~mm}(\mathrm{n}=42)$ in Hualien in August and $161.3 \pm 16.9$ mm $(n=107)$ in Lyudao in November.

The mean $( \pm$ SD) anomalies of the DGIs between the lapillus and asteriscus of the fish were 11.5 \pm 2.7 $(\mathrm{n}=12)$ in June, $11.0 \pm 0.9(\mathrm{n}=5)$ in August and $11.9 \pm 3.4(\mathrm{n}=9)$ in November, and the in situ monthly sea surface temperature (SST) ranged from 25 to $30^{\circ} \mathrm{C}$ (Chang et al. 2012). These values were not significantly different among the sampling months (ANOVA, $\mathrm{p}=0.81$ ). Therefore, by counting the DGIs in the asteriscus of the fish, and adjusting it by adding 11, the age of the juvenile in Taitung was determined to be $38 \mathrm{~d}$, while the mean $( \pm \mathrm{SD})$ ages were $210 \mathrm{~d}(\mathrm{n}=1)$ in Hualien and $160.3 \pm 2.8 \mathrm{~d}$ ( $\mathrm{n}=2$ ) in Lanyu in May, $175.4 \pm 20.4 \mathrm{~d}(\mathrm{n}=30)$ in Lyudao in June, $134.3 \pm 51.9 \mathrm{~d}(\mathrm{n}=10)$ in Hualien in August and $139.3 \pm 28.6 \mathrm{~d}(\mathrm{n}=107)$ in Lyudao in November. Both the lengths and the ages differed significantly between months and could be divided into 2 groups (both $\mathrm{p}<0.05$ ); the larger and older fish were collected in May and June and the smaller and younger ones were collected in August and November.

The von Bertalanffy growth equations computed using FL and daily age of the fish were fitted as follows (Fig. 5):

$$
L_{t}=253.85 \times\left[1-\mathrm{e}^{0.0075 \times(t+1.53)}\right](\mathrm{n}=151)
$$

for wild-collected fish, and

$$
L_{t}=80.36 \times\left[1-\mathrm{e}^{0.0131 \times(t+0.07)}\right](\mathrm{n}=108)
$$

Table 1. Hirundichthys oxycephalus. Length and age of bony flying fish collected in the coastal waters of southeastern

\begin{tabular}{|c|c|c|c|c|c|c|c|}
\hline \multirow{2}{*}{ Month } & \multirow{2}{*}{ Site } & \multicolumn{3}{|c|}{ - Fork length $(\mathrm{mm})$} & \multirow[b]{2}{*}{ Mean \pm SD } & \multirow{2}{*}{$\begin{array}{c}\text { Age }(\mathrm{d}) \\
\text { Range }\end{array}$} & \multirow[b]{2}{*}{$\mathrm{n}$} \\
\hline & & Mean $\pm \mathrm{SD}$ & Range & $\mathrm{n}$ & & & \\
\hline \multirow[t]{3}{*}{ May } & Hualian & 224.4 & 224.4 & 1 & 210 & 210 & 1 \\
\hline & Taitung & 54.0 & 54.0 & 1 & 38 & 38 & 1 \\
\hline & Lanyu & $190.3 \pm 5.2$ & $186.5-193.9$ & 3 & $160.3 \pm 2.8$ & $158-162$ & 2 \\
\hline Jun & Lyudao & $186.5 \pm 9.3$ & $161.9-204.6$ & 35 & $175.4 \pm 20.4$ & $137-227$ & 30 \\
\hline Aug & Hualien & $159.6 \pm 23.1$ & $132.9-204.0$ & 42 & $134.3 \pm 51.9$ & $89-253$ & 10 \\
\hline Nov & Lyudao & $161.3 \pm 16.9$ & $143.5-229.2$ & 107 & $139.3 \pm 28.6$ & $96-254$ & 107 \\
\hline
\end{tabular}
Taiwan in 2009 


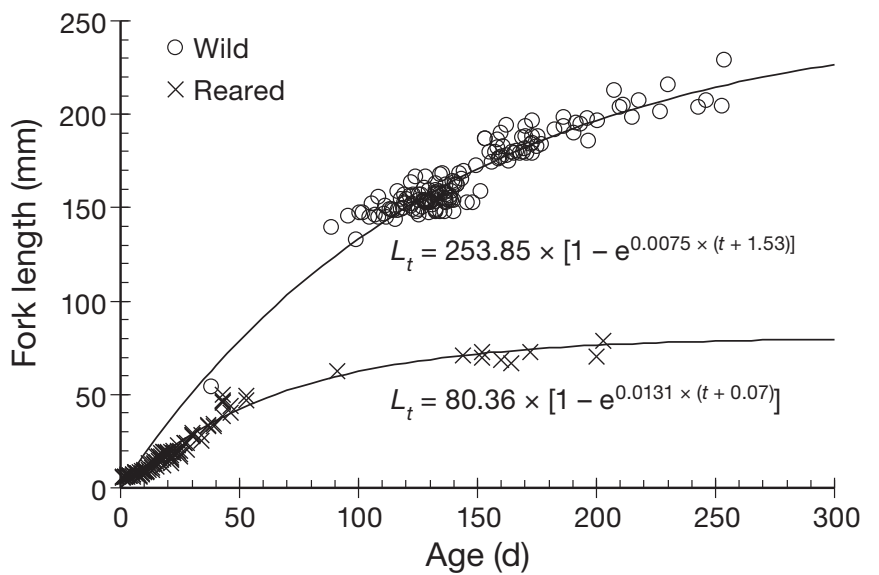

Fig. 5. Hirundichthys oxycephalus. Relationship between age and fork length $\left(L_{t}\right)$ of wild-collected and laboratory-reared bony flying fish

for laboratory-reared fish, where $L=\mathrm{FL}$ and $t=$ time in days.

It was evident that the growth parameters between the wild-collected and laboratory-reared fish were substantially different. The growth coefficient $(k)$ of $0.0075 \mathrm{~d}^{-1}$ for the wild fish was dramatically lower than the $0.0131 \mathrm{~d}^{-1}$ determined for laboratory fish, while the asymptotic length $\left(L_{\infty}\right)$ of $253.86 \mathrm{~mm}$ was much higher for the wild fish than the $80.38 \mathrm{~mm}$ for the laboratory fish.

\section{Hatching date and cohort dynamics of the fish}

The distribution of hatching date of the bony flying fish is shown in Fig. 6a. The fish collected in May 2009 hatched in November or December 2008 or in April 2009, while those collected in June were from hatches in November 2008 to February 2009. The fish collected in August hatched in 2 separate periods, December 2008 to January 2009 and April to May 2009. The fish collected in November 2009 originated from a prolonged hatching period, with the majority of the hatching occurring between May and July 2009.

In general, the bony flying fish off the eastern coast of Taiwan can be divided into winter and summer cohorts with 2 spawning peaks, one in January and one in July (Fig. 6b). The spawning of the summer cohort occurred within the traditional spawning period of these flying fish. Consequently, we had to harvest the eggs and fish under the restrictions of Taiwan's flying fish egg fishery management regulations. The reproductive ecology of the winter cohort of these fish in this area, however, was unknown to date.
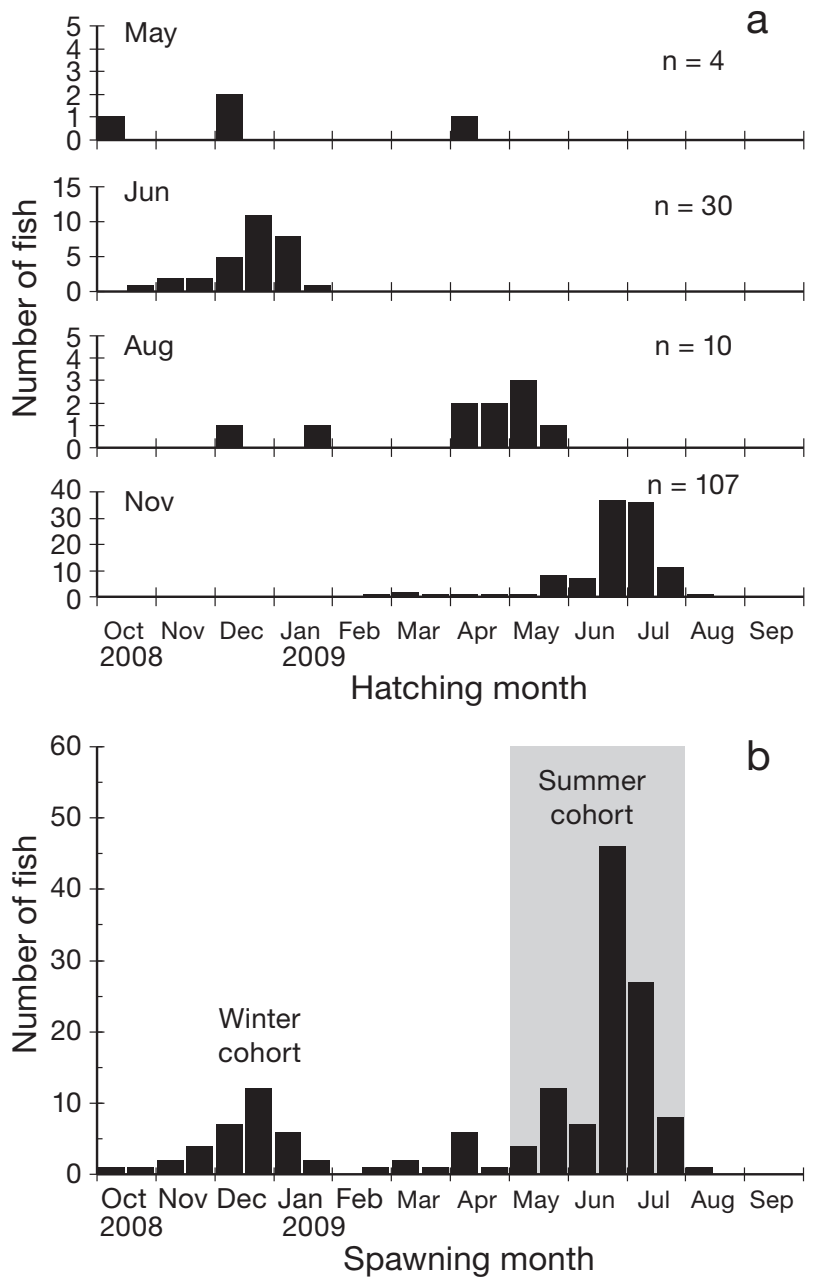

Fig. 6. Hirundichthys oxycephalus. Frequency distributions of back-calculated (a) hatching date and (b) spawning date of bony flying fish. Grey area: duration of the flying fish egg fishery

\section{DISCUSSION}

\section{Asteriscus: the most suitable otolith for age determination of bony flying fish}

Selecting the most suitable otolith pair for age determination as well as the preparation technique, is species-specific, and depends on the quality of resolution, the regularity of the microstructural patterns, objectives of the examination, and considerable technical precedence. Generally, the sagitta is the most frequently chosen, and the lapillus is used particularly for the ostariophysan fishes. Since the asteriscus forms late in the larval development, care should be taken in validating the formation of the first increment by cross-validating the asteriscus microstructure against those of other otoliths (Secor et al. 1992). 
Validating the daily periodicity of the growth increments in otoliths has been attempted by using various methodologies for different otolith pairs for several species of flying fish. The growth increments in the sagitta were initially discarded because they are difficult to prepare (Oxenford et al. 1994, Ichimaru 2005). The daily growth increments in the lapillus of Hirundichthys affinis, H. oxycephalus, Cypselurus heterurus doederleini and C. hiraii, and those in the asteriscus for unknown species of flying fish were validated by applying the fertilized-egg rearing method (Oxenford et al. 1994, Yoneyama 2001, Ichimaru 2005). Those studies mainly validated the ages of fish less than $60 \mathrm{~d}$ post-hatch. In the present study, validation of the daily growth increments in the otoliths of flying fish was rigidly extended to $91 \mathrm{~d}$ post-hatch for the sagitta and $203 \mathrm{~d}$ for the lapillus and the asteriscus. Deposition of the first daily growth increment in the asteriscus was determined to occur $11 \mathrm{~d}$ posthatch, which was similar to 10 to 15 d post-hatch reported by Yoneyama (2001). In addition, the mean anomalies of daily growth increments in the lapillus and the asteriscus showed little variation among the sampling months with different in situ SST conditions. This indicated that the deposition of the first daily growth increment in the asteriscus was not substantially influenced by water temperature or different cohorts. Therefore, considering the convenience and ease of preparation and observation, the asteriscus was taken to be the most suitable otolith to use for age determination of bony flying fish in this study.

\section{Genera-specific age and growth characteristics}

Information on the growth parameters for flying fish is scarce. The present study estimated an $L_{\infty}$ of $253.86 \mathrm{~mm}$ and a $k$ of $0.0075 \mathrm{~d}^{-1}$ for wild-collected Hirundichthys oxycephalus, while for laboratoryreared fish these values were $80.38 \mathrm{~mm}$ and $0.0131 \mathrm{~d}^{-1}$, respectively. This substantial difference suggests that, while a rearing experiment is useful and important for validating the daily growth increment in the otolith, it is inappropriate to combine fish samples from a rearing experiment with wild fish samples for estimating growth parameters for the species. Furthermore, the growth parameters estimated from the laboratory-reared fish should be applied with caution. The higher $k$-value for the laboratory fish might be due to the early abundance of food availability in the artificial rearing environment. The shorter $L_{\infty}$ for the laboratory fish might be attributed to a failed transition of feeding habits in the artificial environment and/or insufficient space to allow activities that might be required for fish growth. On the other hand, the growth parameters estimated from the wild-collected fish are probably closer to the true values. This view is supported by the empirically calculated asymptotic length of 241.16 mm (Pauly 1980) matching the maximum observed length of $229.1 \mathrm{~mm}$ for the wild fish collected in the present study. Similar results were found for the congeneric $H$. affinis from the eastern Caribbean Sea, but with a slightly higher growth rate of $0.00854 \mathrm{~d}^{-1}$ and a shorter asymptotic length of $245 \mathrm{~mm}$ (Oxenford et al. 1994).

\section{Implication of the back-calculated spawning period and cohort dynamics of the flying fish fisheries}

To date, the answer to the question of whether flying fish are synchronous or batch spawners remains controversial (Andrianov \& Lakshminaraina 1994, Hunte et al. 1995, Khohiattiwong et al. 2000). Two spawning periods, one in the summer between May and July and one in the winter from November to December, were discerned from the otolith DGIs and the collection dates of Hirundichthys affinis in the eastern Caribbean Sea (Oxenford et al. 1994). On the other hand, after applying similar otolith DGIs backcalculations, Cypselurus heterurus doederleini, C. hiraii and $H$. oxycephalus off the northeastern coast of Japan showed a prolonged spawning period from May to August (Ichimaru 2005). The present study indicated that the spawning periods of $H$. oxycephalus off the eastern coast of Taiwan took place between May and August and between November and January. This finding coincides with the findings for the congeneric $H$. affinis in the eastern Caribbean Sea (Oxenford et al. 1994) but is inconsistent with those of the 3 species off the northeastern coast of Japan (Ichimaru 2005). This discrepancy might be attributed to the different sampling months used in these studies. Wild fish were collected during the fishing season between August and October in Ichimaru (2005), while in the present study the collection of wild fish was carried out throughout a $1 \mathrm{yr}$ period, and the fish were examined between May and November.

The present study indicated that there were 2 spawning cohorts of bony flying fish off the east coast of Taiwan. This finding has important implications for the resource assessment and management of both the adult flying fish as well as the eggs fisheries. The main fishing season for the eggs of the flying fish is 
from mid-May to mid-July. The high abundance of adults collected in May and June off the southeastern coast of Taiwan is evidence that they originated from a separate winter spawning cohort. Based on the assumption that flying fish spawn synchronously, these 2 cohorts could be regarded as independent units of fish stocks in the management of the fisheries. However, if we assume that these fish are batch spawners, then both cohorts must be interrelated. In that case, a summer cohort overharvesting of the flying fish egg fishery in northeastern Taiwan might provoke a shortage of the winter cohort and consequently result in the decline of the adult flying fish fishery in southeastern Taiwan. Further studies on the reproductive ecology, migratory life history and population genetics of the bony flying fish should prove to be very beneficial for a better understanding of their biology and the impact of the fisheries on these fish.

Acknowledgements. This study was financially supported by the National Science Council (grants NSC98-2611-M110-001 and NSC99-2611-M-110-017) to S.K.C. and C.W.C. It was also the thesis of C.H.L submitted to the National Sun Yat-sen University (NSYSU) in partial fulfillment of the requirements for an MSc degree. The authors are grateful to C. C. Kao, Institute of Marine Biology, NSYSU, for the practical advice on laboratory rearing of the fish, and to J. C. Shiao, Institute of Oceanography, National Taiwan University, and the anonymous reviewers for critical comments.

\section{LITERATURE CITED}

Andrianov DP, Lakshminaraina D (1994) Data on the reproduction of three species of flyingfish (Exocoetidae) in the coastal waters of southeastern India. J Ichthyol 34: $12-26$

Anonymous (2010) Fisheries statistical yearbook Taiwan, Kinmen and Matsu area 2009. Fisheries Agency, Council of Agriculture, Executive Yuan, Taipei

Blake A, Campbell GA (2007) Conflict over flying fish: the dispute between Trinidad \& Tobago and Barbados. Mar Policy 31:327-335

Brothers EB (1980) Age and growth studies on tropical fishes. In: Saila SB, Roedel PM (eds) Stock assessment for tropical small-scale fisheries. Proc Int Workshop, 19-21 September 1979, International Center for Marine Research Development, University of Rhode Island, Kingston, RI, p 119-136

Bruun AF (1935) Flying-fishes (Exocoetidae) of the Atlantic: systematic and biological studies. Dana Rep 2(6):1-106

> Campana SE, Oxenford HA, Smith JN (1993) Radiochemical determination of longevity in flyingfish Hirundichthys affinis using Th-228/Ra-228. Mar Ecol Prog Ser 100: 211-219

Chang SK, Chang CW, Ame E (2012) Species composition and distribution of the dominant flyingfishes (Exocoetidae) associated with the Kuroshio Current, South China Sea. Raffles Bull Zool (in press)
Chen CH (1987) Studies of the early life history of flying fishes (family Exocoetidae) in the northwestern Pacific. Taiwan Mus Spec Publ Ser No.7, Taipei

Dalzell P (1993) The fisheries biology of flying fishes (Families: Exocoetidae and Hemiramphidae) from the Camotes Sea, Central Philippines. J Fish Biol 43:19-32

Hunte W, Oxenford HA, Mahon R (1995) Distribution and relative abundance of flyingfish (Exocoetidae) in the eastern Caribbean. II. Spawning substrata, eggs and larvae. Mar Ecol Prog Ser 117:25-37

Ichimaru T (2005) The life cycle of three species of flyingfish in the north waters of Kyusyu and the recruitment of young flyingfish to the fishing ground. Bull Nagasaki Pref Inst Fish No. 33, Nagasaki

- Khokiattiwong S, Mahon R, Hunte W (2000) Seasonal abundance and reproduction of the fourwing flyingfish, Hirundichthys affinis, off Barbados. Environ Biol Fishes 59:43-60

Lewis J, Brundritt K, Fish AG (1962) The biology of the flyingfish, Hirundichthys affinis. Bull Mar Sci Gulf Caribb 12:73-94

Lipskaya NY (1987) Feeding of flyingfish (Exocoetidae) larvae and fingerlings in the region of the Peruvian upwelling. J Ichthyol 27:108-116

Nelson JS (2006) Fishes of the world, 4th edn. John Wiley \& Sons, New York, NY

Oxenford HA, Hunte W (1999) Feeding habits of the dolphinfish (Coryphaena hippurus) in the eastern Caribbean. Sci Mar 63:303-315

> Oxenford HA, Hunte W, Deane R, Campana SE (1994) Otolith age validation and growth-rate variation in flyingfish (Hirundichthys affinis) from the eastern Caribbean. Mar Biol 118:585-592

> Oxenford HA, Mahon R, Hunte W (1995) Distribution and relative abundance of flyingfish (Exocoetidae) in the eastern Caribbean. I. Adults. Mar Ecol Prog Ser 117: $11-23$

Pauly D (1980) A new methodology for rapidly acquiring basic information on tropical fish stocks: growth, mortality, and stock-recruitment relationships. In: Saila SB, Roedel PM (eds) Stock assessment for tropical smallscale fisheries. Proc Int Workshop, 19-21 September 1979, International Center for Marine Research Development, University of Rhode Island, Kingston, RI, p 154-171

Potts AC, Thomas AD, Nichols E (2003) An economic and social assessment of the flyingfish (pelagic) fishery of Tobago, Trinidad and Toba. Proc Gulf Caribb Fish Inst 54:635-649

Resosudarmo BP (1995) The construction of a bioeconomic model of the Indonesian flyingfish fishery. Mar Resour Econ 10:357-372

Rose CD, Hassler WW (1974) Food habits and sex ratios of dolphin Coryphaena hippurus captured in the Western Atlantic Ocean off Hatteras, North Carolina. Trans Am Fish Soc 103:94-100

Secor DH, Dean JM, Laban EH (1992) Otolith removal and preparation for microstructural examination. In: Stevenson DK, Campana SE (eds) Otolith microstructure examination and analysis. Can Spec Publ Fish Aquat Sci 117, Ottawa, p 19-57

Shao KT (2009) Taiwan fish database (web electronic publication), v. 2009/1. http://fishdb.sinica.edu.tw (accessed 10 Dec 2010) 
Shen SC, Lee SC, Shao KT, Mok HK, Chen CT, Chen CH (1993) Fishes of Taiwan. National Taiwan University, Taipei

Wu CC, Lin JC, Su WC (2006) Diet and feeding habits of dolphinfish (Coryphaena hippurus) in the waters off eastern Taiwan. J Taiwan Fish Res 14:13-27

Yacapin NC (1991) Growth, mortality and recruitment of short-wing flyingfish Oxyphorhampus micropterus in

Editorial responsibility: Matthias Seaman,

Oldendorf/Luhe, Germany
Bohol Sea, Philippines. Fishbyte 9:10-15 www.worldfishcenter.org/Naga/FB_2979.pdf

Yoneyama S (2001) To examine age of coast flying fish by otolith. Tokyoto Suisan Shikenjo Shuyo Seikashu, Heisei 12, Nendo, p 3-4

Zerner C (1986) The flying fishermen of Mandar. Cult Surviv Q 11 (Spec Issue):18-22

Submitted: July 5, 2011; Accepted: March 2, 2012

Proofs received from author(s): May 11, 2012 